\title{
Using a Consensus Conference to Characterize Regulatory Concerns Regarding Bioremediation of Radio- nuclides and Heavy Metals in Mixed Waste at DOE Sites
}

A Report Presented to the U.S. Department of Energy by

Denise Lach and Stephanie Sanford

Oregon State University

September 2006 
Using a Consensus Conference to Characterize Regulatory Concerns Regarding Bioremediation of Radionuclides and Heavy Metals in Mixed Waste at DOE Sites

\section{Table of Contents $\quad$ Page}

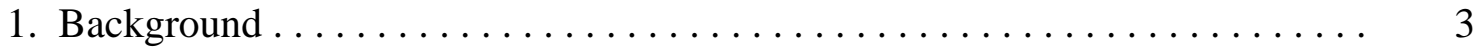

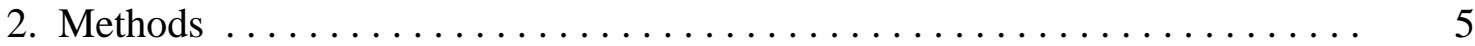

3. Results:

Impact of Participation in Consensus Workshop ................ 6

Effectiveness of Consensus Workshop ....................... 14

4. Conclusions ......................................... 18

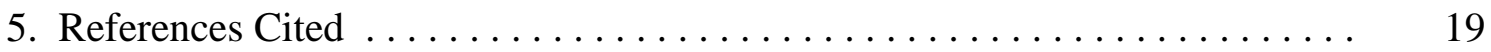

Appendix A. Use of Bioremediation to Treat Radionuclides and Heavy Metals, a Report to US DOE

Appendix B. State Regulations Regarding the Use of Bioremediation

Appendix C. Nine-month Follow-up Interview Protocol 


\section{Background}

Emerging bioremediation technologies appear to offer promising techniques for immobilizing, destroying, or sequestering contaminants at Department of Energy (DOE) sites around the country. Field-scale demonstrations and projects have shown that bioremediation can effectively treat a variety of chemicals at DOE sites including chlorinated solvents (both aerobically and anaerobically), aromatic compounds, and petroleum products. Most recently, bioremediation has shown promise in immobilizing metals and radionuclides through alterations of redox conditions which either change the valence or produce anions that affect solubility (e.g. sulfides). While bioremediation has the advantages of being more "natural" and is often less expensive than chemical or thermal methods, it does have challenges associated with long treatment regimes. Many biochemical reactions, especially at ambient temperatures, are slow and require long induction times and periods for adequate microbial growth. Times to decrease contaminant concentrations or toxicity to levels required by remediation standards are typically measured in years and decades. In the case of immobilization or sequestration of radionuclides and heavy metals, continuous nutrient delivery is likely to be required to sustain the transformation. In addition, radioactive contamination in mixed wastes poses additional problems for all cleanup technologies including bioremediation. Long and complicated treatment periods require continued institutional commitment, monitoring, and intervention, which taken together is often referred to as "stewardship."

The successful implementation of bioremediation ultimately requires regulatory approval from the state agencies responsible for oversight of cleanup activities at the various sites. Regulations governing radionuclide and heavy metal cleanup are somewhat confusing due to multiple agencies, overlapping authority, and various categories of radioactive materials. Regulatory authority rests with three federal agencies - the Nuclear Regulatory Commission (NRC), the Environmental Protection Agency (EPA), and the Department of Energy (DOE) - and the states, which have not reached consensus on regulatory approaches. The regulatory system does not necessarily help accelerate cleanup decisions. While personnel at regulatory agencies may receive training about or information on new technologies through entities such as the Interstate Technology Regulatory Council (ITRC), there is no concerted effort to develop consistent regulatory understanding of the use of bioremediation technologies.

During the winter of 2005, we developed and implemented a "consensus workshop" with state regulators to elicit their concerns and issues regarding the use of bioremediation as a cleanup technology for radioactive nuclides and heavy metals at Department of Energy (DOE) sites around the country. The consensus workshop is a derivation of a technology assessment method designed to ensure dialogue between experts and lay people. It has its origins in the United States in the form of "consensus development conferences" used by the National Institutes of Health (NIH) to elicit professional knowledge and concerns about new medical treatments. Over the last 25 years, NIH has conducted over 100 consensus development conferences. (Jorgensen 1995).

The consensus conference is grounded in the idea that in order to be accepted and sustained, technology assessment and policy must be socially negotiated, rather than narrowly defined by a group of experts. To succeed, non-experts need access to 
information about use of the technology that addresses a full complement of issues including a risk assessment of the organization proposing the technology. The consensus conference method sets up an informed dialogue that makes technology understandable to the non-expert and sets it within perspectives and priorities that may differ radically from those of the expert community. While specific outcomes differ depending on the overall context of a conference, one expected outcome is that consensus conference participants develop greater knowledge of the technology during the conference process and, sometimes, the entire panel experiences a change in attitude toward the technology and/or the organization proposing its use (Kluver 1995).

In the more than 100 consensus conferences conducted by the NIH, an independent, non-federal, non-advocacy panel with appropriate expertise listens to information presented by experts, considers the information, and then composes a consensus statement that addresses the questions and concerns of the panel. Consensus reports focus on the safety and efficacy of the technology, although economic, legal, and ethical issues may be used by the panel and specialists they hear from to provide context. The statement is not a policy statement of the government and the consensus panel is not an advisory body although the government may adopt any or all of the panel's recommendations. The consensus statement is based on publicly available data, reflecting the views of a panel of thoughtful people with the technical ability to examine and discuss the available data. The panel synthesizes information, examines conflicting interpretations, and provides clear and accurate answers to the questions they consider most pressing. Any statement may also include discussion of uncertainty, options, and minority viewpoints.

While all methods of public participation have strengths and weaknesses, the consensus conference ranks high on effectiveness in areas that are of interest at DOE sites (Rowe and Frewer 2000). Specifically, the consensus conference is an effective process for identifying the variety and complexity of attitudes held by the general public regarding bioremediation and creating an understanding that is likely to lead to acceptance of technology strategies. Strengths inherent to the consensus conference include a high degree of participant independence, early participant involvement, transparency of the process to the public, public resource accessibility, clear task definition, and cost-effectiveness. The consensus conference method of defining public concerns also avoids some of the weaknesses of the survey method, especially the tendency for surveys to assume a monolithic general public that is deficient in its understanding of science (Davison et al, 1997). The consensus conference establishes a forum for interactive public consultation and it elicits a more considered range of public concerns.

Importantly with regard to DOE sites, the consensus conference method has strengths that the "citizens' advisory committee" method of public participation does not. The consensus conference supports independence of the participants from the institutions or individuals using or promoting a certain technology or approach, greater transparency of the discussion and recommendation process, greater access to resources, and cost effectiveness (Rowe and Frewer 2000). Also, the consensus conference provides a relatively short-term, finite method for involving the public, which results in a written report of the public issues identified in the process. Limitations of the method, however, include a smaller degree of representativeness than a survey provides and less structuring 
of the decision-making to the extent that would occur in an approach like a citizen's jury/panel.

In earlier research we designed a "workshop" model of the consensus conference approach which focuses educating panel members and producing a consensus report; this model does not include a conference at which the panel presides. We believe the "consensus workshop" is well-suited to the task of educating state regulators about bioremediation of radionuclides and metals.

\section{Research Purpose and Questions}

The purpose of the research was to characterize the concerns of state regulators regarding emerging bioremediation technology to be used to clean-up radionuclides and heavy metals in mixed wastes at US DOE sites. We asked two integrated questions:

1. What impact does participation in a consensus workshop have on the knowledge, attitudes, and practices of state regulators regarding bioremediation technology?

2. How effective is a consensus workshop as a strategy for eliciting and articulating regulators' concerns regarding the use of bioremediation to clean up radionuclides and heavy metals in mixed wastes at U.S. Department of Energy Sites around the county?

After describing the methods we used in this project, each of these questions is discussed in some detail below. A copy of the final report issued by the state regulators participating in the consensus workshop is attached as Appendix A. In summary we found that panel members in general:

- quickly grasped the science related to bioremediation and were able to effectively interact with scientists working on complicated issues related to the development and implementation of the technology;

- are generally accepting of in situ bioremediation, but concerned about costs, implementation (e.g., institutional controls), and long-term effectiveness of the technology;

- are concerned equally about technological and implementation issues; and

- believed that the consensus workshop approach to learning about bioremediation was appropriate and useful.

\section{Methods}

Working with a Steering Committee composed of the Principal Investigators (both sociologists by training), two civil engineers involved in bioremediation, and a staff member of the California EPA, Department of Toxic Substances Control (also involved in bioremediation), we devised a strategy for implementing the project. The Steering Committee recommended that regulators from seven states be invited to participate in the Bioremediation Consensus Workshop: California, Colorado, Idaho, Missouri, South 
Carolina, Tennessee, and Washington. These states all have cleanup activities at US DOE sites, although the extent of activities and state oversight ranged from a completed clean-up at Rocky Flats to a regional water quality program in California. Once the states were selected, it was determined which agency and/or agency branch was responsible for oversight on DOE cleanup projects. That division was contacted and a participant in the consensus workshop was recruited. In most cases, this person was not the Program/Division Head, but rather a member of the department who interacted regularly with the US DOE and relevant state agencies and legislators. For example, the Idaho panelist was the Manager of the State of Idaho INEEL Oversight program.

Prior to the first meeting of the Regulator Panel, each member completed a presurvey assessing their knowledge of and attitudes about bioremediation as well as their sense of the barriers to the use of the bioremediation as a cleanup technology in their state. The same set of questions was asked about six months after the panel completed its work to assess any changes. Panel members were also provided with a white paper on bioremediation developed by the US DOE (Natural and Accelerated Bioremediation Research Program, 2003) and background information about the consensus workshop process. Also during this early period, a summary of state regulations potentially relevant to the use of bioremediation as a clean-up technology was developed (attached as Appendix B). Approximately nine months after the consensus workshop, all but one of the panel members was interviewed individually about their current knowledge, experience, and attitudes regarding the use of bioremediation.

The panel met two times, the first in January 2005 and again in February 2005. This is a reduction of about one-third the recommended amount of time for consensus workshops, but was designed to allow busy professionals to participate in both sessions. Participants did "homework" prior to each session and may have provided information to the facilitator and/or PIs between sessions. Both workshop sessions were facilitated by a professional mediator. Notes were taken during all sessions for use in the following analyses. During the first session, regulators learned more about the science of bioremediation, developed their first round of questions regarding the technology, and identified the types of experts they would like to hear from prior to writing their report. The second session involved (1) conversations with "experts" regarding bioremediation, and (2) drafting, reviewing, and completing a final "consensus" report that they all could sign. Throughout the process, participants were debriefed regarding what worked and what didn't with the consensus workshop method.

\section{Results}

\section{A. Impact of Participation in Consensus Workshop}

All participants were asked to prepare for the workshop by determining any regulatory constraints in their state regulations to the use of bioremediation technology for the cleanup of mixed wastes. In general, they found no explicit rules or regulations on the books, although several regulators believe that any use of bioremediation would be constrained by groundwater rules (for underground injection wells), clean water regulations, and any existing agreements between states and the US DOE. Several also reported that bioremediation is being used in their states for clean up of VOCs, 
petrochemicals, and other wastes so they came into the workshop somewhat familiar with concepts related to bioremediation.

We can determine the impact of the workshop on participants by looking at the kinds of change that occurs in their knowledge and attitudes about bioremediation as measured through pre- and post-workshop surveys and interviews. We review the responses to the survey, analyze the open-ended survey questions, and discuss the results of the six-month follow-up interviews in some detail below. Because the number of responses is so small (10), it is not possible to conduct a rigorous statistical analysis. Consider the discussion below to be specific to panel members' experiences, although we believe they represent a wide range of experience with DOE clean-up activities and knowledge of bioremediation.

\section{Comparison of Pre- and Post-Workshop Surveys}

As evident from Table 1 below, participants gained confidence in what they knew about bioremediation through participation in the conference. They felt particularly wellinformed about regulatory requirements for the use of bioremediation; this may have been a factor of the pre-workshop assignment as described above as well as extended conversations with regulators from other states working on similar issues.

\begin{tabular}{|l|l|l|}
\hline $\begin{array}{l}\text { On a scale of 1-5, where 1 is "not very } \\
\text { well informed" and 5 is "very well } \\
\text { informed, how informed are you about: }\end{array}$ & $\begin{array}{l}\text { Pre-test } \\
\text { mean } \\
\text { mean }\end{array}$ \\
\hline $\begin{array}{l}\text { a. sites where any type of bioremediation } \\
\text { has been or is being used. }\end{array}$ & 3 & 4 \\
\hline $\begin{array}{l}\text { b. the use of bioremediation for } \\
\text { radionuclides and heavy metals. }\end{array}$ & 3 & 4 \\
\hline $\begin{array}{l}\text { c. regulatory requirements for use of } \\
\text { bioremediation for radionuclides and heavy } \\
\text { metals. }\end{array}$ & 3 & 5 \\
\hline $\begin{array}{l}\text { d. the benefits and risks of bioremediation } \\
\text { for radionuclides and heavy metals. }\end{array}$ & 3 & 4 \\
\hline
\end{tabular}

Table 1: How Informed Participants are about Bioremediation

Although participants may feel more informed about bioremediation and their comfort level and confidence in describing bioremediation to others increased slightly, panelists were still uncomfortable with issues related to "microbial species that live in the subsurface" as seen in Table 2 below. This topic was addressed in the workshop through interaction with a microbiologist who raised many issues about this complex science. 


\begin{tabular}{|l|l|l|}
\hline $\begin{array}{l}\text { On a scale of 1-5, where one is "not at all comfortable" and 5 } \\
\text { is "very comfortable," how comfortable would you be } \\
\text { describing to decision-makers the following aspects of } \\
\text { bioremediation of radionuclides and heavy metals: }\end{array}$ & $\begin{array}{l}\text { Pre-test } \\
\text { mean } \\
\text { mean }\end{array}$ \\
\hline a. Valences, bonding, and redox reactions & 2 & 3 \\
\hline b. Metal chemistry: Eh, pH and complexation & 2 & 3 \\
\hline c. Microbial metabolism & 2 & 3 \\
\hline d. Microbial species that live in the subsurface & 2 & 2 \\
\hline e. Environmental monitoring and institutional controls & 5 & 5 \\
\hline
\end{tabular}

Table 2: Comfort Level Describing Bioremediation to Others

We then went on to ask participants how acceptable bioremediation technology was in their states for a variety of clean-up activities as described below in Table 3. As discussed above, many regulators have already seen bioremediation used for cleaning up hydrocarbons and chlorinated solvents, so bioremediation is perceived as an acceptable technology. For clean-up of heavy metals and radionuclides, however, they have not experience and there was no change in the level of acceptability of bioremediation, which remained at a "moderately acceptable" level.

\begin{tabular}{|l|l|l|}
\hline $\begin{array}{l}\text { Based on a scale of 1-5, where } 1 \text { is “not acceptable at all” and } \\
5 \text { is "very acceptable," how acceptable is bioremediation for } \\
\text { treating each of the following compounds: }\end{array}$ & $\begin{array}{l}\text { Pre-test } \\
\text { mean }\end{array}$ & $\begin{array}{l}\text { Post-test } \\
\text { mean }\end{array}$ \\
\hline a. petrochemical hydrocarbons & 5 & 5 \\
\hline b. chlorinated solvents & 4 & 4 \\
\hline c. PCBs & 3 & 3 \\
\hline d. dioxins & 3 & 3 \\
\hline e. heavy metals & 3 & 3 \\
\hline f. radionuclides & 3 & 3 \\
\hline
\end{tabular}

Table 3: Acceptability of Bioremediation for Clean-up of Various Compounds

During the workshop, participants also discussed other types of technologies currently in use for cleanup of heavy metals and radionuclides. We were interested in comparing the acceptability of these technologies with bioremediation. As shown below in Table 4, acceptability of three of the four commonly used technologies for cleaning up hazardous and mixed wastes increased after the workshop; in-situ vitrification alone remained unchanged, and acceptable to participants. As seen in Table 5, the acceptability of bioremediation to participants themselves did not change after the workshop. What did change was their sense that bioremediation would be more acceptable to decision makers in their state given existing state rules and regulations. Again, this may be a factor of the work they did researching their current regulations and conversations with other panelists, as well as increasing their own knowledge and confidence regarding the technology. 


\begin{tabular}{|l|l|l|}
\hline $\begin{array}{l}\text { Based on a scale of 1-5, where } 1 \text { is “not acceptable at all” and } \\
5 \text { is very acceptable, how acceptable to you is each of the } \\
\text { following technologies for cleaning up radionuclides and } \\
\text { heavy metals: }\end{array}$ & $\begin{array}{l}\text { Pre-test } \\
\text { mean }\end{array}$ & $\begin{array}{l}\text { Post-test } \\
\text { mean }\end{array}$ \\
\hline a. chemical treatment & 3.5 & 4 \\
\hline b. physical or hydraulic barriers for contaminants in water & 3 & 3.5 \\
\hline c. capping for contaminants in soil & 3 & 4 \\
\hline d. in-situ vitrification & 4 & 4 \\
\hline
\end{tabular}

Table 4: Acceptability of Currently Used Technologies

\begin{tabular}{|l|l|l|}
\hline $\begin{array}{l}\text { On a scale of 1-5, where 1 is “not acceptable at all” and 5 is } \\
\text { "very acceptable," how acceptable is bioremediation of } \\
\text { radionuclides and heavy metals: }\end{array}$ & $\begin{array}{l}\text { Pre-test } \\
\text { mean }\end{array}$ & $\begin{array}{l}\text { Post-test } \\
\text { mean }\end{array}$ \\
\hline a. to you. & 4 & 4 \\
\hline b. to your state regulatory agency decision-makers. & 3.5 & 4 \\
\hline c. given your existing state rules and regulations. & 3.5 & 4 \\
\hline
\end{tabular}

Table 5: Acceptability of Bioremediation

Finally, we asked participants to identify how serious different barriers were to the use of bioremediation of radionuclides and heavy metals. As shown below in Tables 6-9, the perceived importance of many barriers remained the same or went down after the workshop. It's interesting to note those barriers where panelists reported increased importance after the workshop. Among the institutional barriers, there was an increase in participants' perception of the "tendency of government bureaucracy to use 'status quo' technologies." Perception of the importance of three of the four regulator and legislative barriers went down. Increases in importance were seen in the economic barriers related to a "lack of economic incentives to develop and use bioremediation," and in the technological barriers "limited cost data" and "limited performance data." It is clear that as workshop participants learned more about the use of bioremediation to clean up radionuclides and heavy metals, their perceptions of barrier importance moved away from institutional and regulatory barriers to those related to technology development and implementation.

\begin{tabular}{|l|l|l|}
\hline $\begin{array}{l}\text { Based on a scale of 1-5 where } 1 \text { is "not very important" and 5 } \\
\text { is “very important, How important do you think the following } \\
\text { institutional barriers are to the use of bioremediation for } \\
\text { radionuclides and heavy metals? }\end{array}$ & $\begin{array}{l}\text { Pre-test } \\
\text { mean } \\
\text { mean }\end{array}$ \\
\hline $\begin{array}{l}\text { 1). Lack of coordination by federal and state agencies to } \\
\text { promote and regulate bioremediation. }\end{array}$ & 2.5 & 2 \\
\hline $\begin{array}{l}\text { 2). Tendency of government bureaucracy to use "status quo" } \\
\text { technologies. }\end{array}$ & 3 & 4 \\
\hline $\begin{array}{l}\text { 3). Lack of knowledge by regulators of bioremediation for } \\
\text { radionuclides and heavy metals. }\end{array}$ & 4 & 3.5 \\
\hline
\end{tabular}

Table 6: Importance of Institutional Barriers 


\begin{tabular}{|c|c|c|}
\hline $\begin{array}{l}\text { Based on a scale of } 1-5 \text { where } 1 \text { is "not very important" and } 5 \\
\text { is "very important, how important do you think the following } \\
\text { regulatory and legislative barriers are to the use of } \\
\text { bioremediation for radionuclides and heavy metals? }\end{array}$ & $\begin{array}{l}\text { Pre-test } \\
\text { mean }\end{array}$ & $\begin{array}{l}\text { Post-test } \\
\text { mean }\end{array}$ \\
\hline 1). Inconsistent permitting processes. & 2 & 2 \\
\hline 2). Time- and resource-intensive permitting processes. & 3 & 2 \\
\hline $\begin{array}{l}\text { 3). Inhibition of the use of bioremediation for radionuclides } \\
\text { and heavy metals under RCRA requirements. }\end{array}$ & 3 & 2 \\
\hline 4). Liabilities those users of this technology might incur. & 3 & 3 \\
\hline
\end{tabular}

Table 7: Importance of Regulatory and Legislative Barriers

\begin{tabular}{|c|c|c|}
\hline $\begin{array}{l}\text { Based on a scale of } 1-5 \text { where } 1 \text { is "not very important" and } 5 \\
\text { is "very important, how important do you think the following } \\
\text { economic and financial barriers are to the use of } \\
\text { bioremediation for radionuclides and heavy metals? }\end{array}$ & $\begin{array}{l}\text { Pre-test } \\
\text { mean }\end{array}$ & $\begin{array}{l}\text { Post-test } \\
\text { mean }\end{array}$ \\
\hline $\begin{array}{l}\text { 1). Lack of economic incentives to develop or use } \\
\text { bioremediation of radionuclides and heavy metals. }\end{array}$ & 3 & 4 \\
\hline $\begin{array}{l}\text { 2). Insufficient government and private-sector funding for } \\
\text { development and demonstration of bioremediation of } \\
\text { radionuclides and heavy metals. }\end{array}$ & 3 & 3 \\
\hline
\end{tabular}

Table 8: Importance of Economic and Financial Barriers

\begin{tabular}{|c|c|c|}
\hline $\begin{array}{l}\text { Based on a scale of } 1-5 \text { where } 1 \text { is "not very important" and } 5 \\
\text { is "very important, how important do you think the following } \\
\text { technological barriers are to the use of bioremediation for } \\
\text { radionuclides and heavy metals? }\end{array}$ & $\begin{array}{l}\text { Pre-test } \\
\text { mean }\end{array}$ & $\begin{array}{l}\text { Post-test } \\
\text { mean }\end{array}$ \\
\hline $\begin{array}{l}\text { 1). Limited cost data about bioremediation of radionuclides } \\
\text { and heavy metals. }\end{array}$ & 3 & 3.5 \\
\hline $\begin{array}{l}\text { 2). Limited performance data about bio-remediation of } \\
\text { radionuclides and heavy metals. }\end{array}$ & 4 & 5 \\
\hline 3). Lack of clear standards for performance of the technology. & 4 & 3.5 \\
\hline $\begin{array}{l}\text { 4). Lack of a program to formally verify the performance of } \\
\text { bioremediation of radionuclides and heavy metals. }\end{array}$ & 4 & 3.5 \\
\hline
\end{tabular}

Table 9: Importance of Technological Barriers

Pre- and Post-Workshop Survey Open-ended Questions

The survey also had several open-ended questions through which we asked participants for fuller details about their responses to the survey questions. Of course, participants were not required to answer the open-ended questions so we don't have exact corresponding data between the pre- and post-test surveys. Where we do have answers to both surveys, we can take a look to see if there has been any change in the issues of concern to participants.

One open ended question asked participants about factors that determine the acceptability to them of bioremediation of radionuclides and heavy metals. About half of 
the respondents who provided answers in both the pre- and post-surveys reported similar factors after the workshop as before. In most cases, however, these responses provided more examples and details. For example, one pre-workshop panelist's response required "proven effectiveness" for bioremediation to be acceptable. In the post-workshop survey the idea of effectiveness was extended to "technology [that is] effective in controlling mobility, bioavailability, or toxicity," all issues that were discussed in detail during the workshop.

The other half of the participants identified new issues that affected acceptability. For example, one respondent suggested that as long "as it's an effective tool to meet remedial objectives, bioremediation can be appropriate.” This general assessment of acceptability was modified in the post-workshop survey to reflect more specific concerns:

Given the fact that the chemistry for bioremediation for rads and metals can be reversed, substantive long term stewardship monitoring and maintenance will be critical. I would also want to ensure that failure will not result in an irreversible catastrophe.

Issues related to long term stewardship and institutional controls turned up in all of the responses that changed from the pre- to the post-workshop survey.

We also asked respondents about acceptability of bioremediation to state agency decision makers and given existing state rules and regulations. About two-thirds of the responses were similar on the pre- and post-workshop surveys. Like the question above, respondents tended to provide more detail on the post-workshop surveys.

For the three respondents who provided completely new answers to what would make bioremediation acceptable to state regulatory decision-makers, two identified the critical issues would be related to favorable stakeholder or public opinion. The other respondent shifted from "precedence" as the critical issue for regulators on the pre-workshop survey to identifying more technical issues on the post-survey workshop (e.g., geological analog, field testing data available).

We also asked about how existing state rules and regulations affect the use of bioremediation. As discussed above, a fair bit of time was spent by participants prior to and during the workshop on state regulations, so we expected that the post-survey workshop responses will be more detailed. For the most part, however, responses remained unchanged. In the two cases where new issues were raised on the postworkshop survey, one respondent extended the technical issues that need to be resolved to meet state regulations while the other switched from technical issues to a management issues (i.e., the responsible party (DOE) invests the necessary study (time and funds) to determine if this technology is suitable for application at this site.”

The last question we asked on both the pre-and post-workshop survey was about additional barriers to the use of bioremediation technology in their state. The factor added most often post-workshop regarded difficulty working with stakeholders including other regulators with less information about bioremediation - on issues related to this sophisticated technology. 


\section{Follow-up Interviews}

Finally, we conducted one-on-one interviews with each panelists (except one who was unavailable due to a personal tragedy) about nine months after the workshop to see what had changed, if anything, in their knowledge of, experience with, and acceptability of bioremediation. The interview protocol is included as Appendix D.

About half of the participants had no conversations or work related to bioremediation subsequent to the consensus workshop. Three of the participants had talked with their staff and colleagues about the results of the consensus workshop. One had conversations with contractors about bioremediation and another had professional interests through the ITRC, which is likely to pursue the subject of bioremediation in upcoming educational forums. One participant used the monitoring objectives developed by the group for another project, believing they were relevant to any monitoring effort. One participant summed described his use of the information and report:

When it comes time to consider [bioremediation], I have this thing [the consensus report] in one hand and recommend that my staff have it as working guidance to try and make decisions about this stuff. Because people who haven't thought about this in any detail probably haven't thought that if you turn off nutrients, conditions shift - you need to have bioremediation that winds up as sustainable. The report brings that out.

For the most part, panelists' attitudes about the acceptability of bioremediation remained unchanged since the workshop and they believe that the information they received at the workshop was appropriate and adequate. One mentioned that information from other potential users (e.g., the Department of Defense) might have been helpful. Issues that remain include:

- ongoing field demonstrations of bioremediation,

- stabilization rather than removal of mixed wastes,

- geologic complexity at many DOE sites, and

- the extent of DOE's interest in bioremediation as a clean-up technology.

After reflection, almost all panelists report that the recommendations highlighted in their final report remain the critical issues to be considered when determining the acceptability of bioremediation as a cleanup technology. One suggested that the group could also have considered the role of contractors at the DOE sites and ways to work with them. One participant reported:

DOE is relying heavily on contractors and the technology they propose to do business. What do contractors think of bioremediation? The way DOE leaves things up to the contractors is the biggest issue; the contractors have economic incentives. They have to meet performance standards or liability falls to the contractor, so they are likely to stay away from things like bioremediation. . . . this has changed over the past five years. DOE says "here contractor, here's what you have to achieve and the budget” and if you don’t get it done ... 
This concern was also reflected in the most commonly reported barrier to use of bioremediation economic incentives. As one participant described it:

The lack of economic incentives is probably the main [barrier]. We have a site that's being addressed by a performance-based contract and we're finding initially that they have a certain budget that they're working with and it appears that they're going to be taking the least expensive way out; there isn't a lot of incentive to use bio.

Other barriers to the use of bioremediation include unresolved issues related to long term stewardship and institutional controls required when using bioremediation for mixed wastes. One participant suggested that when "we deal with an element like a metal or rad with a long half life [we need to know] if it is a permanent fix or a reversible reaction." This participant went on to note that "when you talk about metals and rads, all I see DOE signing up for is 100 years for institutional controls; but we may be looking at millions of years.”

About half of the panelists reported that they had good working relationships with the DOE, particularly with the DOE staff working at each site. They described DOE as willing to "tackle the issues" with state regulators, and as good colleagues because "we all have an interest in cleaning up.” As sites move into new phases of cleanup, however, participants raise concerns about new relationships. One participant describes how "the relationship [with DOE] has probably eroded some because we're moving into long term stewardship, we're dealing with new folks - legacy management folks." Most participants report that they trust the DOE, although a few describe experiences (like going to court) that have eroded trust. One participant in particular described a nuanced trust relationship with the DOE:

I guess it depends on if you're talking about DOE as headquarters, as an institution, as an individual - its all over the place. I don't like the word "trust" because it implies some moral value. I think DOE has different perspectives than we do as regulators on risk. . . . I don't trust that what they think is right is what I think is right. I think they are more comfortable with a higher risk. . . . Sometimes when you work more in depth in a field you get more comfortable with it. Sometimes it's because you're more educated, know more about the risk but sometimes is because you've gotten more familiar with it and have forgotten the risk.

One impact of participation in the consensus workshop that we didn't anticipate was the strong relationships that participants built with each other over the five days of meetings. Many of them report communicating with each other about regulatory issues not related to bioremediation because they learned of fellow participants' experiences and expertise. In the follow-up interviews, for example, while most hadn't communicated with other panelists about bioremediation, most had communicated with one or more panel members about other topics. A few also reported contacting the scientists and engineers who acted as "experts" for the consensus workshop. As one panelist reported, 
I co-lead the radionuclides team at ITRC, both [another workshop participant] and I presented our report to them, sent it to them, had discussions with them. . . We met as a team in San Francisco and in Memphis at the end of October. [One of the "experts"] was there; I dragged him over to our meeting. He showed some slides, background, and a new chart from the one he showed in February; he ... presented his latest thoughts. We have asked him to give guidance on putting together a product.

In some sense, workshop participants and "experts" have created a professional network of people involved with regulatory issues related to the implementation of bioremediation of mixed wastes. They feel comfortable turning to each other with management and technical questions, and know where to turn for expert information.

\section{Summary of Impacts}

In summary, we found that state regulators participating in the consensus workshop started with a relatively sophisticated knowledge of state regulations regarding bioremediation, some experience and knowledge of bioremediation through its use with VOCs and other wastes, and a general interest in learning more about a technology that could help them in their clean-up objectives. For the most part, participation increased their knowledge of the strengths and limitations of bioremediation as well as a range of state and federal regulations, and created a professional network of regulators and experts interested in and working on clean-up activities at DOE sites around the country. Most panelists believe that state regulations are not a major barrier to the use of bioremediation of radionuclides and heavy metals in mixed waste at DOE sites but they still don't feel totally comfortable talking with their boss or others about the specifics of how bioremediation works (although comfort levels increased slightly from pre- to postworkshop).

\section{B. Effectiveness of Consensus Workshop}

We use the following questions drawn from the literature reported above to assess the effectiveness of the consensus workshop:

- Did the workshop identify the variety and complexity of citizen attitudes about bioremediation?

- Were the participants independent from institutions and/or individuals promoting specific technologies and/or approaches?

- Was the workshop process transparent to the participants?

- Was there clear task definition that is reflected in finished products?

- Was the workshop cost effective?

As mentioned above, one of the strengths of a consensus workshop is its ability to elicit a more considered range of public concerns about an issue. While scientists and government agencies may have their own ideas about what does or should concern the public (or, in this case, state regulators), other issues may exist. The consensus workshop 
provides the opportunity to articulate concerns perhaps not imagined by those familiar with a given technology.

Before the panel was selected, we asked the Steering Committee to identify the concerns they believed state regulators might have about bioremediation of radionuclides and metals. They agreed that the institutional, regulatory and legislative, economic and financial, and technological barriers described in the EPA report (2000), represented the possible concerns of state regulators. In the pre-survey, the panel members identified additional barriers such as "public understanding and acceptance," "[the] historical track record of this application," and rather sophisticated technical barriers such as "are mobility and/or toxicity reduced to an acceptable level," and "whether accumulation/sequestration of heavy metals and radionuclides [has] created a new problem by creating a low level burial ground..." Survey responses following the consensus workshop show that state regulators came away with highly technical concerns or felt affirmed in their earlier concerns regarding issues like public acceptance. Importantly, the consensus report produced by the state regulators carefully lays out their concerns and includes an entire section on "the state regulator perspective." (See Appendix A, pp 8-9.) Lastly, in the final interviews, all of the respondents say they continue to stand by the contents of their report and believe it reflects the concerns of state regulators.

As a public involvement strategy, the consensus conference works best if the lay panelists are independent from institutions and/or individuals promoting specific technologies and/or approaches. This may be most important in the "conference" stage of the process where members of the public may be more apt to trust a lay panel with independent members. We believe it is also important in the "workshop" setting as a way to promote learning and sharing among the panel members. From our experience, the "neutrality" of panel members and experts is an issue for participants throughout the process. For this project, we made sure to create a panel of state regulators only and not include federal employees or individuals linked to the DOE in some way. The state regulator panelists commented on the importance of "neutrality" in the group; one panelist put it this way in the final interview:

The more I think about it, the more I think I wouldn't expand the group to include DOE or contactors. I think part of the reason people could talk freely and have a conversation rather than talking at each other was because we were all regulators; but if DOE is in the room, I might have some concerns about what I say.

In their consensus report, the state regulators themselves highlight the importance of independence from a different angle; i.e., by commenting on the potential for "group think" in the process:

A consensus workshop setting may be susceptible to "group think" mentality. Participation of well-chosen, impartial experts reduces the susceptibility. Repeated reviews of draft reports with workshop participants may reduce this susceptibility as well. 
Rowe and Frewer (2000) point out that independence may also be established by using a Steering Committee of individuals from diverse and/or neutral organizations; they use the example of "university academics." In this consensus workshop, as well as others, we have found that panelists perceive the university sponsors and presenters to be neutral and they identify this as a positive aspect of the process.

Another strength of the consensus conference as a public involvement strategy is its transparency; that is, the public sees what is going on and how decisions are made. Transparency was a significant feature of the state regulators consensus workshop also. With the guidance of a skilled facilitator, the state regulators on the panel openly decided everything from how they would schedule their time to what kinds of information and expertise they would seek during the process. Importantly, their final report was their own, and not something they felt manipulated or cajoled into writing. As mentioned above, nine months after the consensus report was written, every panelist interviewed said they continued to be pleased with the report; most commented on its thoroughness and accuracy.

In this workshop, as well as others we are familiar with, there is another type of transparency that aids in learning and reaching consensus - hearing scientists and experts talk and engage in discourse about decisions related to the technology in question. The state regulators put it this way in their consensus report:

One additional positive aspect of the workshop was combining research scientists and regulators to tackle a set of issues; this exposes scientists to regulators as peers and reasonable decision makers. It allowed regulators to be exposed to and interact with the research scientists rather than merely reading research information.

In the post-survey, one panelist commented:

I am still satisfied with the process. The level of expertise and candidness of the technical experts is necessary for any state regulator considering application of bioremediation.

And, in the final interview we heard several comments like the following:

[The consensus workshop] certainly allowed for all parties to air their concerns, to ask questions; nobody was embarrassed, [it] was very open and I thought that was good.

One challenge in engaging the public in decision-making is clearly defining the scope of the task so that confusion and disputes are avoided. We designed the consensus workshop to address this challenge throughout the process. The state regulator workshop began in January with a group exercise in which the panel developed a "charter" that included a mission, anticipated schedule, expected outcomes, compensation, and conduct (see page 13 in Appendix A). The charter was referred to throughout the workshop when questions arose about purpose of the research or the process. The charter can be modified to add clarity, which is something the state regulator panel chose to do at the beginning of their meetings in February. Evidence that 
this worked to keep the panel on task is contained in the consensus report where the panelists list "clear scope of work" as the first item in describing what worked well in the consensus workshop. That section of the report is reproduced below.

\section{Use of a Consensus Workshop as a Tool}

The group believes that a consensus workshop can be a worthwhile process and could be useful in examining other technical issues.

This consensus workshop worked well for several specific reasons including:

- Clear scope of work - the group understood its charge to evaluate the merit of a technology and consider its regulatory acceptance.

- A limited and manageable group size with common objectives.

- Membership included appropriate regulators with a mix of technical and policy knowledge.

- The group members were familiar with implications of the application of the technology.

- Topic of keen interest to the participating states.

- A good educational forum for those participants.

- Good, flexible facilitation.

- Participants were encouraged that the workshop has potential to influence US DOE research priorities.

Cost is an important criterion when considering the effectiveness of a public involvement strategy. Unfortunately, most of the literature on public participation methods does not contain detailed information about costs. Also, since any method may be implemented in any number of ways, cost is difficult to generalize. Our own opinion is that the costs of a consensus workshop of this type are moderate and reasonable given the positive outcomes of this approach. In this case, state regulators committed 5 days over a 2-month period, without additional pay, to learn about bioremediation of radionuclides and metals. The project paid for their travel, accommodations, and food. Additional costs included travel, lodging, and food for 5 experts and the same, plus pay, for a professional facilitator. Meeting room and supplies costs were minimal. We, the researchers, served as staff for the workshop; other workshop budgets would need to take account of the costs of staff and office support. 


\section{Conclusions}

Prior to this research project, we heard from US DOE staff, scientists, and even the previous lay panel, that one of the largest barriers to successful implementation of bioremediation was state regulations and regulators. Yet, on closer examination, it appears that (1) there are no existing state regulations specifically restricting bioremediation if it meets existing standards for underground injections (which are regulated in most states), and (2) state regulators as represented by our panelists are open to working with DOE and others on new technologies that help meet their clean-up goals.

As discussed above, state regulators worked easily with scientists to learn about the technology, were able to frame critical regulatory issues in a written report, and expressed increased confidence in their knowledge of bioremediation. According to panelists, the consensus workshop was an effective method for learning about bioremediation and communicating their concerns and questions about the technologies.

Although panelists knew they were involved in a "research project" regarding the use of the consensus workshop for eliciting input from regulators, they wanted decision makers at US DOE to read their report, know they are willing to work with DOE regarding innovative approaches to clean-up at their sites, and consider a strong relationship between states and the DOE as critical to any effective clean-up. They do not want perceive themselves to be and do not want others to perceive them as barriers to successful clean-up at their sites. 


\section{References Cited}

Davison, A., I. Barns, and R.Schibeci. 1997. Problematic Publics: A Critical Review of Surveys of Public Attitudes to Biotechnology. Science, Technology \& Human Values 22 (3): 317-348.

Jorgensen, T. 1995. Consensus Conferences in the Health Care Sector. Pp 17-29 in S. Joss and J. Durant, editors, Public Participation in Science: the Role of Consensus Conferences in Europe. London: Science Museum.

Kluver, L. 1995. Consensus Conferences at the Danish Board of Technology. In S. Joss and J. Durant, editors, Public Participation in Science: the Role of Consensus Conferences in Europe. London: Science Museum. 41-49.

Rowe, G. and L.J. Frewer. 2000. Public Participation Methods: A Framework for Evaluation. Science, Technology \& Human Values 25 (1): 3-27.

U.S. Environmental Protection Agency. 2000. An Analysis of Barriers to Innovative Treatment Technologies: Summary of Existing Studies and Current Initiatives. Solid Waste and Emergency Response. 
Appendix A: Use of Bioremediation to Treat Radionuclides and Heavy Metals, a Report to US DOE

\section{State Regulators \\ Consensus Workshop}

\section{Use of bioremediation to treat radionuclides and metals}

\section{Areport to US DOE}

\section{February, 2005}


The members of the State Regulators Consensus Workshop: Use of Bioremediation to Treat Radionuclides and Metals accept and endorse this report by their signatures.

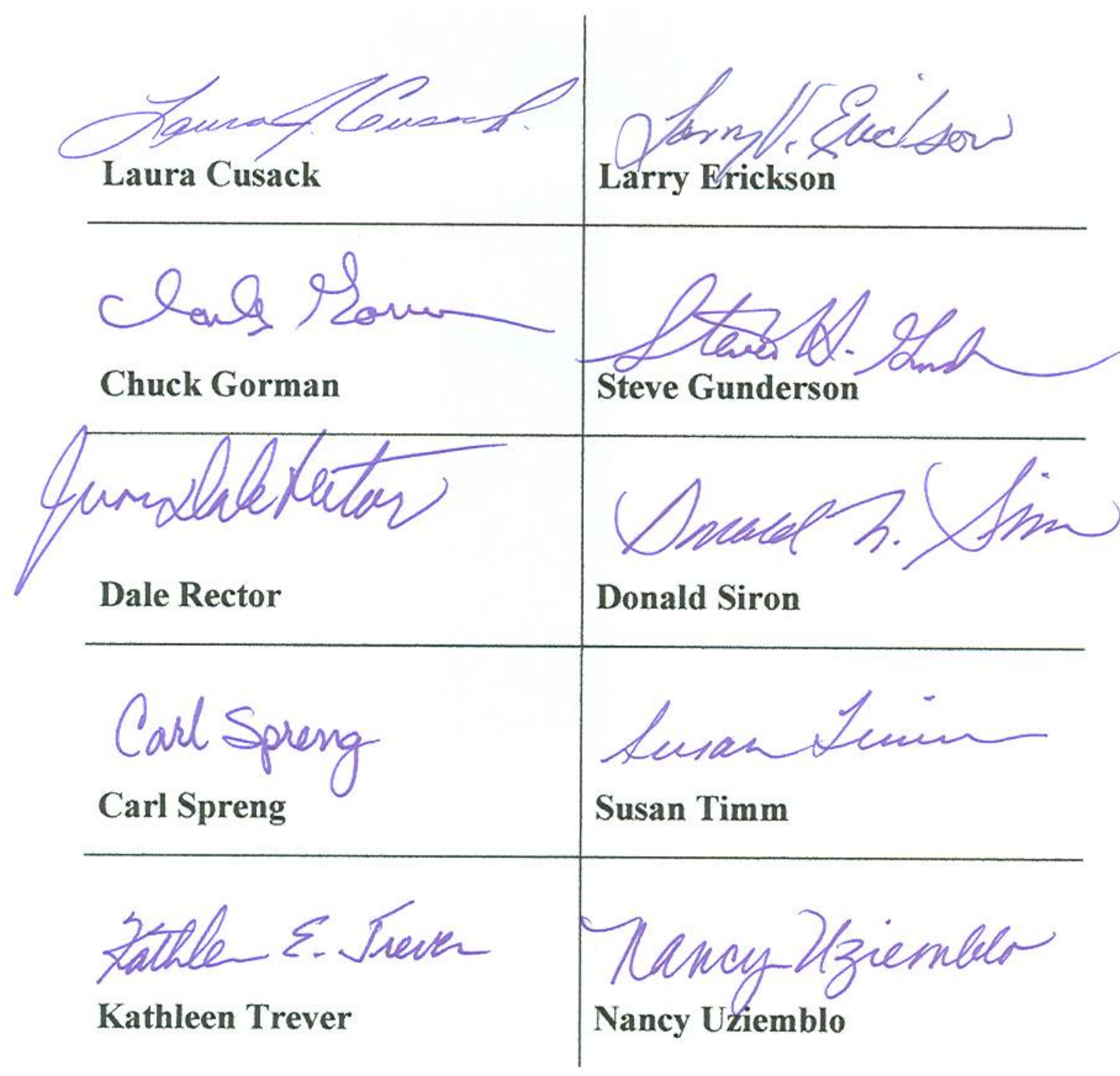

State Regulators Consensus Workshop

Consensus Report

February, 2005

Page 21 


\section{Table of Contents}

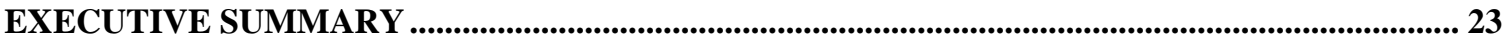

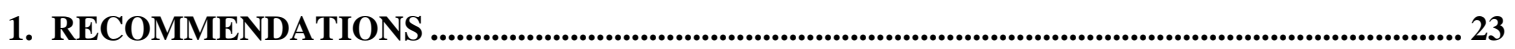

USE OF BIOREMEDIATION FOR RADIONUCLIDES AND METALS CONTAMINATION ….................................. 24

Implementation Opportunities for Bioremediation of Radionuclides and Metals ................................ 24

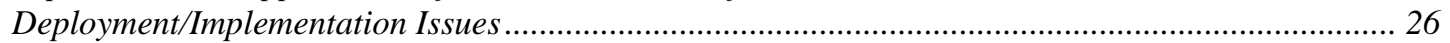

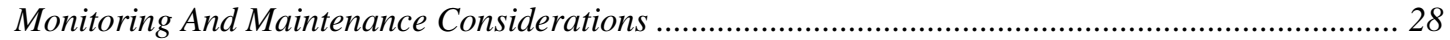

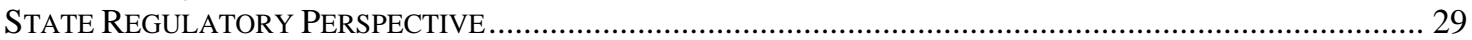

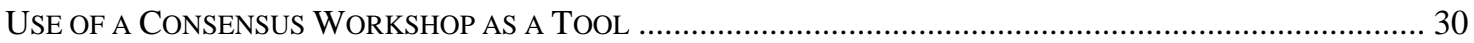

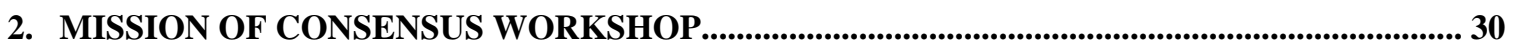

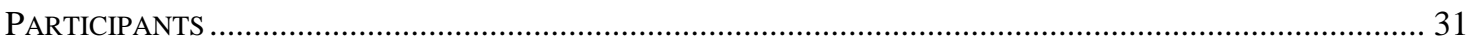

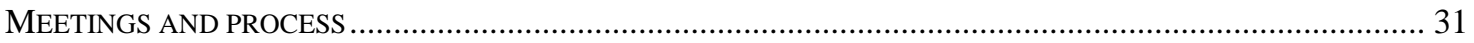

3. STATE REGULATORY FRAMEWORK ............................................................................................ 33

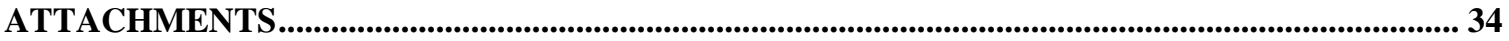

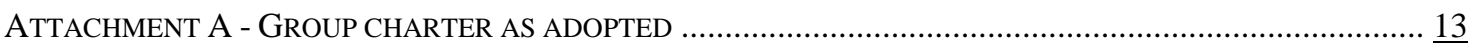

ATTACHMENT B - CONTACT INFORMATION FOR WORKSHOP PARTICIPANTS ......................................... $\frac{13}{15}$

ATTACHMENT C - TECHNICAL AdVISORY COMMITTEE MEMBERS ........................................................... $\underline{16}$ 


\section{Executive Summary}

The State Regulators Consensus Workgroup evaluated bioremediation of radionuclides and metals as a cleanup option at US Department of Energy (US DOE) sites ${ }^{1}$.

This report provides a state perspective on what factors should be considered in prioritizing research on the topic. The US DOE should view state regulators as partners for implementation of bioremediation for radionuclides and metals, not as obstacles. States want permanent solutions and consistently demonstrate a willingness to consider innovations or alternative technologies that meet cleanup goals.

For the states to consider bioremediation among remedial options, the states must have:

- Confidence in the technology prior to full-scale application,

- Adequate site characterization,

- Adequate maintenance and performance monitoring, and

- Commitment to long-term stewardship.

It is apparent that this remediation tool has not progressed further than a few pilot field applications. Additional research is a key recommendation to US DOE. Research priorities should focus on:

- Real life problems,

- Situations where no other proven, cost-effective technologies exist, and

- Areas with most potential for broad application.

\section{Recommendations}

This consensus workshop of state regulators focused on examining the potential use of bioremediation to treat legacy radionuclides and metals at US Department of Energy (US DOE) sites, with the hope of influencing how US DOE spends its research dollars. The group worked in two sessions to learn about bioremediation, hear from experts, and prepare this report.

Information about legacy radionuclides and metals at US DOE sites are detailed in Bioremediation of Metals and Radionuclides... What it is and how it works, 2003.

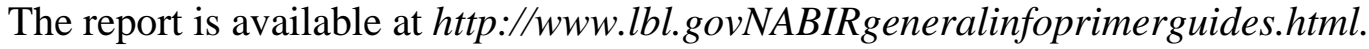

The group examined three areas for recommendations:

1. The use of bioremediation for radionuclides and metals contamination,

2. The state regulatory perspective, and

3. The use of a consensus workshop as a tool.

\footnotetext{
${ }^{1}$ Phytoremediation technologies were not within the scope of this project.

State Regulators Consensus Workshop

Consensus Report

February, 2005

Page 23
} 


\section{Use of Bioremediation for Radionuclides and Metals Contamination}

Bioremediation is a viable option for the remediation of radionuclides and metals. It appears that research is progressing in this area; lab work has been conducted and field studies have started. However, there have been few completed field studies and even fewer large-scale applications of bioremediation to treat radionuclides and metals. In order to expand options beyond the traditional treatment technologies more research is needed.

For the states to consider bioremediation among remedial options, the states must have:

- Confidence in the technology prior to full-scale application

- Adequate site characterization

- Adequate maintenance and performance monitoring

- Commitment to long-term stewardship

States have approved cleanup using bioremediation for solvents and hydrocarbons where bioremediation has resulted in degradation of the target contaminants. However, bioremediation for radionuclides and metals involves stabilization, extraction, or in some cases, alteration to a less toxic form, but does not result in degradation, except for radioactive decay.

Research priorities should focus on:

- Real life problems,

- $\quad$ Situations where no other proven, cost-effective technologies exist, and

- Areas with most potential for broad application.

In developing our recommendations, consensus workshop members focused on three key areas that are discussed in more detail below:

1. Implementation opportunities for bioremediation of radionuclides and metals,

2. Deployment and implementation issues, and

3. Monitoring and maintenance considerations.

\section{Implementation Opportunities}

The group recognizes that the research on bioremediation of radionuclides and metals is relatively new and does not want to close the door on any possibilities at this point. The following table identifies the characteristics that would influence the acceptability of bioremediation for a particular application. Some of these factors may be competing; these factors must be balanced in making remediation choices. The table can also be used to guide US DOE in setting research priorities. These factors are not listed in priority order.

\begin{tabular}{|l|l|}
\hline \multicolumn{1}{|c|}{ More Promising } & \multicolumn{1}{c|}{ Less Promising } \\
\hline $\begin{array}{l}\text { Less potential for hazardous byproducts } \\
\text { such as methyl mercury, or mobilization of } \\
\text { hazardous by-products }\end{array}$ & $\begin{array}{l}\text { Potential for hazardous byproducts such as } \\
\text { methyl mercury, or mobilization of } \\
\text { hazardous by-products }\end{array}$ \\
\hline $\begin{array}{l}\text { Reduced long-term operations, } \\
\text { surveillance, and monitoring (e.g., } \\
\text { radionuclides with shorter half-lives) }\end{array}$ & More long term stewardship requirements \\
\hline $\begin{array}{l}\text { State Regulators Consensus Workshop } \\
\text { Consensus Report } \\
\text { February, 2005 } \\
\text { Page 24 }\end{array}$
\end{tabular}




\begin{tabular}{|l|l|}
\hline Failure does not result in a catastrophe & Failure could result in a catastrophe \\
\hline $\begin{array}{l}\text { Geochemical environment does not have to } \\
\text { be changed drastically to make } \\
\text { bioremediation work }\end{array}$ & $\begin{array}{l}\text { Geochemical environment has to be } \\
\text { changed drastically to make bioremediation } \\
\text { work }\end{array}$ \\
\hline $\begin{array}{l}\text { Lower concentrations of contaminants (not } \\
\text { source of contamination) }\end{array}$ & Higher concentrations of contaminants \\
\hline Stable end products & Reaction easily reversible \\
\hline
\end{tabular}




\begin{tabular}{|c|c|}
\hline More Promising & Less Promising \\
\hline Simple waste and site conditions & $\begin{array}{l}\text { Complex waste, competing reactions, and } \\
\text { complex site geochemistry }\end{array}$ \\
\hline $\begin{array}{l}\text { Technology process incorporates } \\
\text { contaminant into the mineral structure } \\
\text { (reaction will be more difficult to reverse) }\end{array}$ & $\begin{array}{l}\text { Technology process sorbs contaminant onto } \\
\text { the surface of the material }\end{array}$ \\
\hline $\begin{array}{l}\text { A geological analog exists that is stable } \\
\text { under natural conditions }\end{array}$ & No geological analog \\
\hline Other cost-effective remedy is unavailable & Proven cost effective alternatives available \\
\hline $\begin{array}{l}\text { Technology process has been demonstrated or } \\
\text { observed. Those contaminants for which research } \\
\text { results are promising include: } \\
\text { - Technetium } \\
\text { - Iodine } \\
\text { - Uranium } \\
\text { - Strontium } \\
\text { - Chromium } \\
\text { - Mercury } \\
\text { - Lead }\end{array}$ & $\begin{array}{l}\text { Technology process has not been demonstrated to } \\
\text { date. Those contaminants where research has not } \\
\text { been done or results have not been promising: } \\
\text { - Tritium } \\
\text { - Cesium } \\
\text { - Plutonium } \\
\text { - Thorium } \\
\text { - Radium }\end{array}$ \\
\hline $\begin{array}{l}\text { This list is based on technical information } \\
\text { presented at the workshop. }\end{array}$ & $\begin{array}{l}\text { This list is based on technical information } \\
\text { presented at the workshop. }\end{array}$ \\
\hline
\end{tabular}

\section{Deployment/Implementation Issues}

For bioremediation technologies to be used, specific deployment and implementation aspects must be addressed. These include:

1. Adequate hydrogeological characterization

Hydrology and lithology should be characterized within the area of concern.

Porosity, hydraulic conductivities, and other important characterization parameters should be well enough known to establish at least a conceptual model of groundwater behavior. The model should be reviewed by peers, regulators, and stakeholders, and should be routinely updated as appropriate. Public confidence and perception may be improved with demonstration of both the geological characterization and bioremediation method. Hydrogeologic factors to be considered include:

- The site should exhibit predictable groundwater flow. 
- Interfaces between different permeabilities are optimal sites for biological activity, therefore known interfaces can be used to apply bioremediation to a better advantage.

- Complex geologies, such as fractured bedrock and karst, are difficult to bioremediate and monitor. Groundwater flows are often unpredictable and channelized.

- Dry conditions may limit bioremediation without a carrier for the nutrients.

- The vadose zone is difficult to remediate. However, conversion of contaminants to and delivery of nutrients in a gas phase may provide additional bioremediation options in the vadose zone.

2. Adequate geochemistry characterization

Knowledge of subsurface geochemistry is necessary to determine if the reactants required for bioremediation to occur exist in the subsurface. Also, the existence of compounds that would prevent or slow bioremediation must be identified. Bioremediation could cause unwanted mobilization of contaminants of natural constituents, such as arsenic, or co-contaminants.

3. Using bioremediation as a secondary or polishing technique for caps, landfills and inplace disposal

Bioremediation can be used as a secondary or polishing technique for caps, landfills, or in-place disposal units. Some revision of standard landfill engineering techniques may be needed since landfills are generally designed to be as dry as possible. Incorporating bioremediation into the original remediation design is preferable. However, bioremediation could be used later to augment a failed remedy to meet environmental cleanup objectives.

4. Using bioremediation to mobilize a contaminant for extraction

Mobilization of a contaminant can be considered in hydrogeological conditions conducive for extraction. However, care must be taken because if mobilization and extraction fail, the mobilization may worsen environmental conditions by spreading contaminants and/or increasing exposure.

5. Using bioremediation to stabilize a contaminant Stabilization should be considered when treatment or removal is not feasible. Stabilization that results in the formation of a geological analog (i.e., natural, stable end state under ambient conditions) is preferable. In this case, ending nutrient injection would not reverse the effects. 
Stabilization that requires continued nutrient injection would be a secondary preference. Considerations for the continued use of nutrient injection would include cost, long-term effectiveness, permanence, and monitoring requirements.

\section{Monitoring and Maintenance Considerations}

Carefully crafted monitoring and maintenance programs are central to state regulatory approval of bioremediation technologies. The State Regulators Consensus Work Group makes these suggestions for bioremediation project monitoring:

1. Match performance monitoring parameters to remediation objectives. Robust monitoring plans can focus on the direct contamination, contaminant indicators, or the conditions necessary for the desired reactions. Depending on the selected remediation, appropriate screening indicators might include:

- Contaminants and decay products

- Key reactants and byproducts

- $\mathrm{pH}$

- Oxidation/reduction

- Saturation index

- Gross alpha, gross beta, and/or gamma radiation

- Hydrological conditions

- Soil gas

2. Incorporate flexibility in the monitoring plan. Monitoring needs may increase or decrease over time, with changing geochemical conditions, and radioactive decay.

3. Establish and operate a monitoring network sufficient to identify the effects of the remedy, any need for changes, the remedy success or failure.

4. Identify leading indicators of failure or deviation from expected treatment results and establish contingencies for enhanced monitoring, model updates, and possible remedy review.

5. Consider monitoring requirements up front during design of the remediation system to ensure long-term, cost-effective and practical monitoring networks.

6. Long-term remediation systems require long-term budget commitments.

7. Maintenance requirements must include appropriate institutional controls.

8. Maintenance and monitoring requirements must be part of the periodic regulatory remedy reviews.

9. In general, stabilization and isolation remedies will leave contaminants in place and require more long-term monitoring. Extraction remedies, which mobilize contaminants for removal, may require less long-term monitoring. However, extraction remedies will require more short-term 
monitoring to determine effectiveness, identify run-away contaminants, and provide assurance that mobilized contaminants are captured.

\section{State Regulatory Perspective}

States use various criteria to select cleanup remedies. These may include Resource Conservation and Recovery Act ( RCRA) criteria and state-specific requirements in addition to the nine criteria included in the Comprehensive Environmental Response, Compensation, and Liability Act (CERCLA) or Superfund, for cleanup decisions.

The nine CERCLA criteria evaluated for cleanup decisions are:

1. Protection of human health and the environment

2. Compliance with Applicable or Relevant and Appropriate Requirements (ARARs)

3. Long-term effectiveness and permanence

4. Toxicity, mobility or volume reduction through treatment

5. Short-term effectiveness

6. Implementability

7. Cost

8. State agency acceptance

9. Community acceptance

US DOE should not view state regulations, or state regulators, as obstacles to implementation of bioremediation for radionuclides and metals. States want permanent solutions and have demonstrated a willingness to consider innovative technologies that can meet cleanup goals.

Successful deployment of bioremediation requires the following ingredients:

- US DOE must accept state authority in making cleanup decisions. Policy battles over issues like state authority to regulate radionuclides tend to polarize the parties and hamper regulators' willingness to be flexible.

- When bioremediation for radionuclides and metals leaves contamination in place, US DOE must commit to appropriate longterm stewardship and accept the state's role in development and enforcement of federal long-term stewardship obligations. Without this commitment, states are reluctant to support technologies that leave contaminants in place for a long time.

- Given the complexity and uncertainties involved, successful design and implementation of bioremediation is likely to take time and considerable discussion. Clear communication and collaboration are key to success. US DOE must commit to working with states, starting 
with early involvement in defining problems and identifying priorities for applied research.

\section{Use of a Consensus Workshop as a Tool}

The group believes that a consensus workshop can be a worthwhile process and could be useful in examining other technical issues.

This consensus workshop worked well for several specific reasons including:

- Clear scope of work - the group understood its charge to evaluate the merit of a technology and consider its regulatory acceptance.

- A limited and manageable group size with common objectives.

- Membership included appropriate regulators with a mix of technical and policy knowledge.

- The group members were familiar with implications of the application of the technology.

- Topic of keen interest to the participating states.

- A good educational forum for those participants.

- Good, flexible facilitation.

- Participants were encouraged that the workshop has potential to influence US DOE research priorities.

The structure of the workshop allowed time for ideas to evolve; conducting the workshop over several different periods of time allowed time for reflection and honing of ideas. An additional element of the workshop that worked well was breaking into smaller groups to write report elements; smaller groups are more efficient and minimize the influence of dominant voices in the group.

One additional positive aspect of the workshop was combining research scientists and regulators to tackle a set of issues; this exposes scientists to regulators as peers and reasonable decision makers. It allowed regulators to be exposed to and interact with the research scientists rather than merely reading research information.

A consensus workshop setting may be susceptible to "group think" mentality. Participation of well-chosen, impartial experts reduces the susceptibility. Repeated reviews of draft reports with workshop participants may reduce this susceptibility as well.

It is important to stress that the ultimate value of the consensus workshop to the participants will be the feedback they receive from US DOE with regard to how the group's recommendations were considered in making research decisions.

\section{Mission of Consensus Workshop}

The mission of this consensus workshop was to test a method of characterizing state agency regulatory concerns regarding use of bioremediation to clean up radionuclides and heavy metals at US DOE sites around the US. This was a research project. It tested

State Regulators Consensus Workshop

Consensus Report

February, 2005

Page 30 
the use of a consensus workshop to provide feedback to US DOE on remediation options, including research priorities, with a focus on bioremediation techniques for use in treating radioactive and/or heavy metal contaminated sites.

The consensus workshop panel had an opportunity through this process to report to US DOE on both process and technical issues related to cleanup plans.

This consensus workshop was not directly involved in making environmental remediation decisions at any US DOE site.

\section{Participants}

Participants were selected from states with US Department of Energy facilities with ongoing remediation projects. The Steering Committee and other contacts assisted in identifying potential state regulators that might be interested.

Ten regulators from seven states participated in the workshop:

- Laura Cusack, Washington State Department of Ecology

- Larry Erickson, Missouri Department of Natural Resources

- Chuck Gorman, South Carolina Department of Health \& Environmental Control

- $\quad$ Steve Gunderson, Colorado Department of Public Health \& Environment

- Dale Rector, Tennessee Department of Environment \& Conservation

- Don Siron, South Carolina Department of Health \& Environmental Control

- Carl Spreng, Colorado Department of Public Health \& Environment

- Susan Timm, California Central Valley Regional Water Quality Control Board

- Kathleen Trever, Idaho Department of Environmental Quality

- Nancy Uziemblo, Washington State Department of Ecology

Ken Niles, Oregon Department of Energy, participated in the January session only.

\section{Meetings and Process}

The group met in Phoenix, Arizona on two occasions: January 13 \& 14, 2005 and February 16, 17 \& 18, 2005.

The January portion of the workshop included a presentation from Dr. Terry Hazen of the Lawrence Berkeley National Laboratory, explaining the work of the US DOE Natural and Accelerated Bioremediation Research (NABIR) program, the scientific principles underlying bioremediation treatment of metals and radionuclides, and the positive and negative aspects of the treatment technology. A copy of his presentation is available from Oregon State University (OSU). The group also developed a list of questions for the expert panel to address.

The February portion of the workshop involved presentations by the invited experts and drafting of the recommendations and report. The invited experts were:

- Dr. Brian B. Looney, Savannah River National Laboratory

State Regulators Consensus Workshop

Consensus Report

February, 2005

Page 31 
- Dr. Jack Istok, OSU

- Dr. Yoshiko Fujita, Idaho National Laboratory

The presentations from the technical experts are available from OSU.

State Regulators Consensus Workshop

Consensus Report

February, 2005

Page 32 


\section{State Regulatory Framework}

The chart below summarizes in general terms the regulations that might apply to bioremediation of radionuclides and metals.

\begin{tabular}{|c|c|c|c|c|c|c|c|c|}
\hline Issue & CA & $\mathrm{CO}$ & ID & MO & OR & SC & $\mathbf{T N}$ & WA \\
\hline $\begin{array}{l}\text { Regulations do not } \\
\text { encourage or } \\
\text { discourage } \\
\text { bioremediation }\end{array}$ & $\checkmark$ & $\checkmark$ & $\checkmark$ & $\checkmark$ & $\checkmark$ & $\sqrt{ }$ & $\sqrt{ }$ & $\checkmark$ \\
\hline $\begin{array}{l}\text { MCLs }{ }^{2} \text { used as } \\
\text { groundwater cleanup } \\
\text { standards }\end{array}$ & & $\checkmark$ & $\checkmark$ & $\checkmark$ & & $\checkmark$ & $\checkmark$ & $\checkmark$ \\
\hline $\begin{array}{l}\text { State groundwater } \\
\text { cleanup standards } \\
\text { lower than MCLs }\end{array}$ & $\checkmark$ & $\begin{array}{l}\checkmark \\
\text { (for } \\
\text { some } \\
\text { stds) }\end{array}$ & & & & & & $\sqrt{ }$ \\
\hline $\begin{array}{l}\text { Operate the federal } \\
\text { RCRA }^{3} \text { program for } \\
\text { EPA }\end{array}$ & $\checkmark$ & $\checkmark$ & $\checkmark$ & $\checkmark$ & $\checkmark$ & $\checkmark$ & $\checkmark$ & $\checkmark$ \\
\hline $\begin{array}{l}\text { Experienced with } \\
\text { bioremediation of } \\
\text { petroleum and solvent } \\
\text { contamination }\end{array}$ & $\checkmark$ & $\checkmark$ & $\checkmark$ & $\sqrt{ }$ & $\sqrt{ }$ & $\sqrt{ }$ & $\sqrt{ }$ & $\sqrt{ }$ \\
\hline $\begin{array}{l}\text { Formalized cleanup } \\
\text { agreement with } \\
\text { federal facility }\end{array}$ & $\checkmark$ & $\checkmark$ & $\checkmark$ & & & $\checkmark$ & $\sqrt{ }$ & $\sqrt{ }$ \\
\hline $\begin{array}{l}\text { Injection controlled } \\
\text { by UIC }{ }^{4} \text { regulations, } \\
\text { permit and/or add'l } \\
\text { requirements }\end{array}$ & $\checkmark$ & $\checkmark$ & $\checkmark$ & $\checkmark$ & $\checkmark$ & $\checkmark$ & $\checkmark$ & $\checkmark$ \\
\hline $\begin{array}{l}\text { Wastewater } \\
\text { controlled by NPDES } \\
\text { regulations }\end{array}$ & $\checkmark$ & $\checkmark$ & $\checkmark$ & $\checkmark$ & $\checkmark$ & $\checkmark$ & $\sqrt{ }$ & $\checkmark$ \\
\hline $\begin{array}{l}\text { Soil cleanup } \\
\text { standards set by state }\end{array}$ & $\checkmark$ & $\checkmark$ & $\checkmark$ & & $\checkmark$ & & Possibly & $\checkmark$ \\
\hline $\begin{array}{l}\text { US DOE site cleanup } \\
\text { under CERCLA } \\
\text { program }\end{array}$ & $\sqrt{ }$ & $\checkmark$ & $\checkmark$ & $\checkmark$ & & $\sqrt{ }$ & $\sqrt{ }$ & $\checkmark$ \\
\hline $\begin{array}{l}\text { US DOE site cleanup } \\
\text { under RCRA prog }\end{array}$ & & $\checkmark$ & $\checkmark$ & $\checkmark$ & & $\checkmark$ & $\checkmark$ & $\checkmark$ \\
\hline
\end{tabular}

${ }^{2}$ Maximum Contaminant Levels as set by EPA under the Safe Drinking Water Act; risk based decision if no MCL exists

${ }^{3}$ Resource Conservation \& Recovery Act

${ }^{4}$ Underground Injection Control regulations set by EPA under the Safe Drinking Water Act

${ }^{5}$ National Pollutant Discharge Elimination System regulation set by EPA under the Clean Water Act

${ }^{6}$ Comprehensive Environmental Response Compensation and Liability Act State Regulators Consensus Workshop Consensus Report

February, 2005

Page 33 


\section{Attachments}

Attachment A - Group charter as adopted

Attachment B - Contact information for workshop participants

Attachment C - Technical Advisory Committee members 


\title{
Attachment A - Group Charter as Adopted
}

\author{
Consensus Workshop Panel \\ Characterizing Regulatory Concerns Regarding Bioremediation of Radionuclides and \\ Heavy Metals in Mixed Wastes at DOE Sites
}

\section{Charter}

\section{Mission}

The mission of this consensus workshop is to test a method of characterizing state agency regulatory concerns regarding use of bioremediation to cleanup radionuclides and heavy metals at US Department of Energy sites around the US. This is a research project. It will test use of a new technique - - a consensus workshop - - as a method to provide feedback to US DOE on remediation options, including research priorities, with a focus on bioremediation techniques for use in treating radioactive and heavy metal contaminated sites.

The consensus workshop panel has an opportunity through this process to communicate with US DOE on both process and technical issues related to waste cleanup plans.

This consensus workshop will not be directly involved in environmental remediation decisions at any US DOE site.

\section{Anticipated Schedule}

The schedule for the workshop panel includes meetings in Phoenix, Arizona as follows:

\begin{tabular}{c|c} 
Dates & Anticipated Meeting Schedule \\
\hline Thursday, January 13, 2005 & $\begin{array}{l}\text { 8:30 am - 5 pm; working meeting after } \\
\text { dinner }\end{array}$ \\
\hline Friday, January 14, 2005 & $8: 30 \mathrm{am}-3 \mathrm{pm}$ \\
\hline Wednesday, February 16, 2005 & $8: 30 \mathrm{am}-5 \mathrm{pm}$ \\
\hline Thursday, February 17, 2005 & $\begin{array}{l}\text { 8:30 am - 5 pm; working meeting after } \\
\text { dinner }\end{array}$ \\
\hline Friday, February 18, 2005 & $8: 30 \mathrm{am}-3 \mathrm{pm}$
\end{tabular}

\section{Expected Outcomes}

The final expected outcome of the consensus workshop will be a written report documenting the panel's consensus on the regulatory concerns regarding use of bioremediation of radionuclides and heavy metals in waste sites at US DOE locations. The report should include recommendations regarding the use of this type of consensus workshop approach for knowing and understanding state regulatory agency concerns around specific treatment technologies at US DOE sites.

Staff from Oregon State University will assist the consensus workshop panel in developing the report and in production of the report, but the substance of the report will be written and directed by the consensus workshop panel members.

The consensus workshop panel members will accept and personally endorse the written report with their signatures on the final copy.

State Regulators Consensus Workshop

Consensus Report

February, 2005

Page 35 
Key milestones in developing the written report will be:

1. Inventory state regulations related to potential use of bioremediation for treating radionuclides and heavy metals.

2. Learn of bioremediation techniques that could treat legacy pollution problems involving radionuclides and heavy metals.

3. Inventory key questions regarding the use of bioremediation for waste radionuclide and heavy metal contamination.

4. Profile desired technical expertise for addressing key questions. Meet with technical experts.

5. Reach consensus recommendations for US DOE on the possible use of bioremediation for treating radionuclides and heavy metal contamination problems. Include recommendations on how US DOE might best fit proposed bioremediation projects into the states' regulatory schemes.

6. Advise US DOE on the use of consensus workshops as a tool.

7. Pull all the information into a single written report. Gain approval for the document from all workshop consensus panel members. Signify approval by signing the report.

\section{Compensation}

All travel expenses will be paid by Oregon State University.

\section{Conduct}

To the extent possible, the group will attempt to reach consensus on the content of the report. Where not possible, minority reports may be developed.

A facilitator will assist the group in meeting organization and in reaching its goal of developing a final written report.

The group members will treat each other and the professional staff involved in the project with courtesy and respect.

Revised and Adopted by Panel, 1/13/05

Revised and Adopted by Panel, 2/17/05

State Regulators Consensus Workshop

Consensus Report

February, 2005

Page 36 


\section{Attachment B - Contact information for workshop participants}

Laura Cusack, Manager

Tank Waste Treatment and TPA Section

Nuclear Waste Program

Washington State Department of

Ecology

3100 Port of Benton Blvd.

Richland, WA 99354-1670

509-372-7891 lcus461@ecy.wa.gov

Larry Erickson

Federal Facilities Section

Hazardous Waste Program

Missouri Department of Natural

Resources

P.O. Box 176

Jefferson City, MO 65102-0176

573-751-6838

larry.erickson@dnr.mo.gov

Charles (Chuck) Gorman, Manager

Federal Facility Section

Bureau of Land and Waste Management

South Carolina Department of Health

and Environmental Control

2600 Bull Street

Columbia, SC 29201

803-896-4058 gormancm@dhec.sc.gov

Steve Gunderson, Rocky Flats Project

Coordinator

Hazardous Materials \& Waste

Management Division

Colorado Department of Public Health

\& Environment

4300 Cherry Creek Drive South, HMWMD-B2

Denver, CO 80246-1530

303-692-3367

steve.gunderson@state.co.us

Ken Niles, ${ }^{7}$ Assistant Director

Oregon Department of Energy
625 Marion Street NE

Salem, OR 97301-3742

503-378-4906 ken.niles@state.or.us

Dale Rector

Tennessee Department of Environment and Conservation

761 Emory Valley Rd

Oak Ridge, TN 37830

865-481-0995 dale.rector@state.tn.us

Donald L. Siron, P.G., Technical

Coordinator

Federal Facility Agreement Section

Bureau of Land and Waste Management South Carolina Department of Health and Environmental Control

2600 Bull Street

Columbia, SC 29201

803-896-4089 sirondl@dhec.sc.gov

W. Carl Spreng, Project Manager

Corrective Action Projects

Hazardous Materials \& Waste

Management Division

Colorado Department of Public Health

\& Environment

4300 Cherry Creek Drive South, HMWMD-B2

Denver, CO 80246-1530

303-692-3358 carl.spreng@state.co.us

Susan Timm

Central Valley Regional Water Quality

Control Board

11020 Sun Center Drive \# 200

Rancho Cordova, CA 95670-6114

916-464-4657

stimm@waterboards.ca.gov

${ }^{7}$ Participated in January workshop only State Regulators Consensus Workshop Consensus Report

February, 2005

Page 37 
Kathleen Trever, Administrator

Division of INL Oversight \& Radiation

Control

Idaho Department of Environmental

Quality

1410 N. Hilton

Boise, ID 83706

208- 373-0428 ktrever@deq.idaho.gov
Nancy Uziemblo, Geologist/Environmental Specialist Nuclear Waste Program

Washington State Department of Ecology

3100 Port of Benton Blvd. Richland, WA 99354-1670

509-372-7928 nuzi461@ecy.wa.gov 


\author{
Attachment C - Technical Advisory Committee members \\ Janet Gillaspie \\ Environmental Strategies, LLC \\ 537 SE Ash, Suite 12 \\ Portland, Oregon 97214 \\ 503-233-3980 \\ janet@envirostrategies.com
}

Paul Hadley

California EPA, Department of Toxic Substances Control

301 Capitol Mall, $1^{\text {st }}$ Floor

Sacramento, CA 945814

916-324-3823

phadley@dtsc.ca.gov

Denise Lach

Center for Water and Environmental Sustainability

210 Strand Agriculture Hall

Oregon State University

Corvallis, OR 97331

541-737-5471

denise.lach@oregonstate.edu

Stephanie Sanford

Center for Water and Environmental Sustainability

210 Strand Agriculture Hall

Oregon State University

Corvallis, OR 97331

541-737-5861

stephanie.sanford@oregonstate.edu

Lewis Semprini

Civil, Construction, and Environmental Engineering

204C Merryfield

Oregon State University

Corvallis, OR 97331

541-737-6895

lewis.semprini@oregonstate.edu

Kenneth Williamson

Civil, Construction, and Environmental Engineering

202 Apperson

Oregon State University

Corvallis, OR 97331

541-737-6836

kenneth.williamson@oregonstate.edu

State Regulators Consensus Workshop

Consensus Report

February, 2005

Page 39 


\section{Appendix C: Semi-Structured Interview Protocol}

1. Since the consensus workshop, what kind of conversations or work related to bioremediation of radionuclides/metals have you had?

- Did any information, conversation, or new relationship from the workshop change how you do approach regulating clean-up?

2. At this point, six months later, how acceptable is bioremediation to you as technology for cleaning up radionuclides and heavy metals?

- What issues are still questions for you?

- Did you get enough/the right kind of information at the consensus workshop to help you think about this issue? If not, what was missing?

3. Looking back now at the recommendations made by the participants in the Consensus Report for the use of bioremediation for radionuclides and metals contamination, what do you think of them?

- Use of bioremediation for rads/metals contamination

- State regulators’ perspective

- Use of consensus workshop as a tool

- Deployment/implementation issues

- Would you add other recommendations?

4. At this point in time, what are the biggest barriers to using bioremediation for radionuclides and metals in your state?

- Long-term stewardship

- Institutional controls

- Liabilities you may incur

- Lack of economic incentives

5. How would you describe DOE's commitment to working with you on clean up of radionuclides and heavy metals?

- Has it chanced since the Consensus workshop?

- How much do you trust DOE on clean up of radionuclides and heavy metals?

6. Thinking about it now, what are the strengths and limitations of the consensus workshop?

- Have you talked to others about the content/process?

- Are you in touch with people you met at the workshop?

- What other ways are you learning about clean-up technologies?

- Did any experience with the consensus workshop process change how you approach decisions about clean-up technologies?

What questions do you have of us

State Regulators Consensus Workshop

Consensus Report

February, 2005

Page 40 